\title{
Culture: Mediating Individual Consumption and Environment
}

\author{
Christina YP Ting ${ }^{1}$ \\ ${ }^{1}$ Swinburne Institute for Social Research, Swinburne University of Technology, Melbourne, Australia
}

\begin{abstract}
In view of $21^{\text {st }}$ century challenges such as climate change, resource depletion, and increasing population and consumption, would a one-size-fits-all approach to encourage less resource consumption be the solution to sustainable living in a carbon- and resource-constrained world? Conventional factors such as individuals' attitudes and intentions towards resource saving actions, and socio-economic factors such as income and household size are shown to have influence on consumption behaviours. An understanding of these factors is necessary but not sufficient in multicultural Australia with its high affluence and urban livability - high consumption and an ecological footprint $(E F)$ which is one of the largest in the world. Australia's population is increasingly more heterogeneous due to migration from different countries and cultures, especially from Asian, non-English speaking countries. As culture impacts on a spectrum of behaviours and activities, there is a need to develop a deeper understanding of the influence of migrants' ethnic cultures on their post-migration consumption level (as measured by EF) and also whether there are variabilities in consumption behaviours between migrants and Australia-born group. Identifying the challenges and barriers these two groups face in relation to sustainable living and resource consumption will ascertain new avenues to facilitate communication and engagement by governments and service providers to encourage behaviour change for sustainable living. This paper examines how migrants' connectedness to ethnic culture affects their consumption behaviours. The study proposes and tests the CALD (Culturally and Linguistically Diverse) Index to investigate the effect of cultural connectedness on consumption behaviours (as measured by the ecological footprint). Quantitative method comprising questions in consumption categories of energy, water, food, travel, housing and waste generation and management are applied in studying 61 China-born migrants and 72 Australia-born residents in Melbourne. Multi-variate analyses of the surveyed population found that explanatory factors of consumption reinforced well-established determinants, such as income, environmental awareness and dwelling size. However, it also identified the importance of individuals' connectedness with ethnic culture. In particular, individuals who indicated a stronger connectedness with Chinese culture than with the host culture were likely to be higher consumers of energy, travel, housing and appliances. This shows that, in order to alleviate environmental impact, an individual's ethnic culture has to be considered. Development of the cultural indicator, the CALD Index, adds insights into individual lived and cultural experiences, providing a greater depth of understanding of individuals' behaviours and values in relation to consumption and sustainability.
\end{abstract}

Keywords: culture, consumption, environment, sustainability, migrants, behaviour, CALD, multicultural societies

\section{Introduction}

In Australia, an increasingly heterogeneous population adds complexity to the challenges of dealing with increasing population and consumption, and environmental issues such as climate change and resource depletion. The continuous changes in its population structure are due to the increasing migrants who came from Asia, nonEnglish speaking countries [1]. Settling in Australia, these migrants' consumption behaviours are likely to be influenced by their ethnic and the host cultures. Research [2-3] has shown that migrants tend to adopt and imitate the host behaviours. With Australia's high consumption and an ecological footprint that is one of the highest in the world [4], migrants' adoption of the host societal behaviours would have added impact on its environment and resources. In order to alleviate these impacts, it is thus necessary to understand the factors that influence the migrants' consumption behaviours and to what extent their behaviours differ from that of the Australia-born group. Numerous studies [5-6] have frequently found that socio-economic and demographic factors such as income, household size, and dwelling type are determinants of consumption categories such as energy, water and travel by households and individuals. However, relatively little research has focused on culture - particularly ethnic culture - as a determinant of consumption behaviours related to sustainable living 
and resource consumption. This raises the question whether different culture has influence on ethnic groups' behaviour, especially migrant and Australia-born groups.

For Australia, it is critical to understand how culture influences its multicultural groups' consumption behaviours especially the China-born migrants, who make up the largest non-English speaking group in Australia in recent times. This paper, as part of a larger work [7], examines how migrants' connectedness to ethnic culture (as measured by the CALD (Culturally and Linguistically Diverse) Index affects their consumption behaviours (as measured by the ecological footprint, EF). The influential factors on consumption ranging from socio-economic to the CALD Index are explored to seek a better understanding of both migrants and Australia-born residents' footprints. Findings will aid in targeting better specific interventions and policies related to consumption and the environment which need to penetrate all groups within Australian society.

This paper therefore examines the determinates of consumption including the cultural context - the CALD Index, as uniquely applied in this research, that influence the China-born migrants and Australia-born residents in Melbourne, Australia.

\section{Method}

\subsection{Study design}

The questions in this study are derived based on past studies on consumption [8-11] that have shown that a range of determinants is associated with one of more consumption categories such as energy, water, food, housing, travel, waste management and generation. These determinants can be categorised as individual structural attributes such as gender and income, household size and type, and dwelling size, type and tenure. As the pathway to reduce resource consumption and GHG emissions is to better understand the link between individuals' aggregate consumption and environmental impact [10-11], there is a need to include individual attributes. In this study, behavioural attributes such as conservation behaviours, environmental awareness and installation of resource-efficient technologies are categorised into Conservation Behaviours Index (CBI), Environmental Awareness Index (AI) and Resource-efficient technologies Index (REI) respectively. Each Index correspondingly is a summation of components that pertain to energy and water conservation behaviours, awareness of environment-related issues and installation of energy and water efficient technologies.

Past studies [12-13] have shown that culture influences individual's everyday consumption. Little research is on connectedness to ethnic culture on individuals' everyday consumption in the context of sustainable living. Sustainable living, in this study, refers to limiting individuals' resource consumption and greenhouse gas (GHG) emissions [14-15]. These limitations are equated to significantly reduced use of resources and generation of waste. The cultural influence in everyday living can be examined using different indicators of cultural context. This study proposes the CALD (Culturally and Linguistically Diverse) Index, as a measure of connectedness to ethnic culture. The computation of the CALD Index (for more details, refer to [7]) is represented as follows:

CALD Index $=\sum$ Ethnicity + Language + Religion + Food + Festivals + Interactions + Cultural identity

The CALD Index is a scale depicting distinctiveness of ethnic culture. From the summation of the seven indicators, a minimum score of 12 indicates strong connectedness with the host culture while a maximum score of 48 indicates strong connectedness with Chinese culture.

\subsection{Participants}

Interviews were conducted with 61 China-born migrants and 72 Australia-born residents in the suburbs around Box Hill in Melbourne, Australia. The participants were recruited based on the criteria summarised in Table I. The emphasis on post 1995 migration was to focus on the cohort associated with the major recent surge of China-born migrants to Australia - a trend that is expected to continue. 
TABLE I: Criteria used to assess participant's eligibility

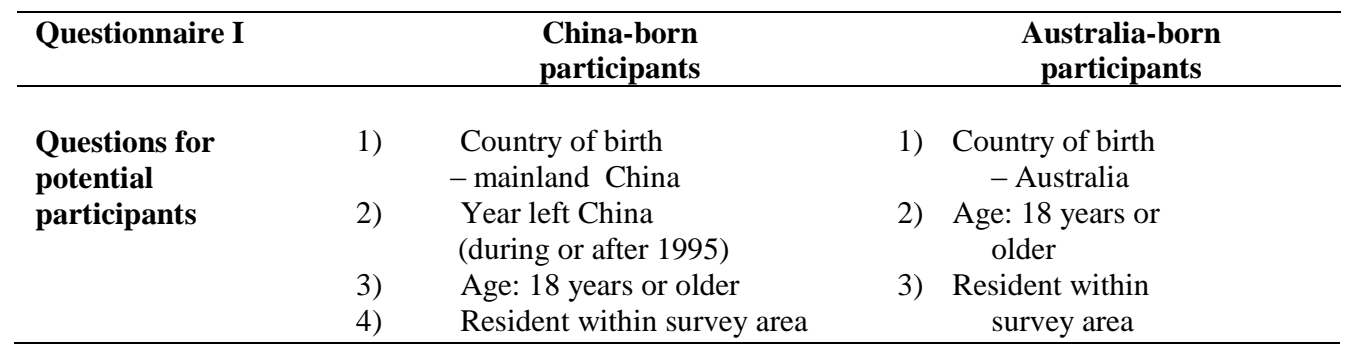

Participants were 29 males and 71 females aged from 18 to 65 and over. The majority of participants was tertiary students $(61.1 \%)$ and lived with family members $(74 \%)$. About 70 per cent of them lived in separate dwellings and 44 per cent were home owners.

\subsection{Questionnaires}

The questionnaires were designed to elicit information that enabled the calculation of ecological footprints and the measurement of the factors influencing attitudes to environment and consumption. The first aspect was using the Centre for Sustainable Economy's [16] ecological footprint calculator. The outputs from the ecological footprint calculator consist of an individual's total ecological footprint and the four components of the ecological footprint: Carbon, Food, Housing, and Goods and Services. The second aspect was to measure both the influential established factors - ranging from individual structural attributes like socio-economic status - and indicators of cultural context, such as ethnicity, language, food, religion, festivals, social interaction, and cultural identity. The inclusions of questions on cultural context enabled formulation of the CALD index.

The questionnaires comprised quantitative questions ranging from socio-economic status to household size and dwelling size, type and tenure, and social interactions and resource conservation behaviours and environment awareness. The questionnaire administered to the China-born migrants was in both Chinese and English versions. Drawing upon the participants' responses, the data was compiled to calculate the size of individual ecological footprint and statistical analysis using SPSS was carried out to find the determinants that have influence on their consumption levels (as measured by EF).

\subsection{Statistical analysis}

Multi-variate analysis [17] is applied to the total sample population in order to better understand the different explanatory power of each variable in relation to the four footprint components and the total ecological footprint. As the total sample size was 133 (consisting of 61 China-born and 72 Australia-born participants), 14 determinants (Table II) were selected for the analyses. This selection adheres to Francis' [20] proposal that a minimum of five cases per determinant is considered suitable for multiple regression. The findings show that there are few very strong correlations between any of the individual determinants and the dependent variable, confirming the suitability of the application of all 14 determinants in the analyses. The outputs from the analyses of the four footprint components and the total ecological footprint were found to have no multicollinearity and there was an absence of outliers.

TABLE II: Determinants of Consumption

\begin{tabular}{|c|c|}
\hline Individual structural attributes & $\begin{array}{l}\text { - Income } \\
- \text { Age } \\
\text { - Education } \\
\text { - Employment } \\
\text { - Income } \\
\text { Car ownership }\end{array}$ \\
\hline $\begin{array}{l}\text { Individual behavioural attributes } \\
\text { (indexes) }\end{array}$ & $\begin{array}{ll}\text { - } & \text { Conservation Behaviours Index (CBI) } \\
\text { - } & \text { Resource-efficient Technologies Index } \\
& \text { (REI) } \\
\text { - } & \text { Environmental Awareness Index (AI) }\end{array}$ \\
\hline $\begin{array}{l}\text { Cultural context } \\
\text { Household context } \\
\text { Dwelling context }\end{array}$ & $\begin{array}{ll}\text { - } & \text { CALD Index } \\
\text { - } & \text { Household size } \\
\text { - } & \text { Dwelling type } \\
\text { - } & \text { Dwelling size } \\
\text { - } & \text { Tenure } \\
\end{array}$ \\
\hline
\end{tabular}




\subsection{Findings}

Table III shows the outputs of the multi-variate analyses that identified the respective strengths of influence of the set of determinants on the four footprint components and the total ecological footprint (dependent variables). Across the four footprint components, different factors were found to exert an influence. Education was the only factor found to have no significant impact on the footprints. The Housing footprint has the most number of determinants, at nine. Six determinants were found to have a significant influence on the total ecological footprint. The Food footprint has the least number of significant determinants, at two. Those determinants measured at individual levels have been shown to exert more influence on these footprint components than those at the household level and in the dwelling context. This detailed breakdown by footprint components representing the key consumption categories creates a better understanding of an individual's consumption behaviours, as opposed to one that focuses on the total ecological footprint. The relative contribution (Beta value) of each factor also differs. For the total ecological footprint, the most significant determinants were the individual behavioural factors (CBI, AI) and income, with dwelling and car ownership also being important contributors. Gender plays a highly significant role in only one of the footprint components - Food.

The analyses have importantly found that the CALD Index, which represents a key cultural factor in the research framework, was found to be a determinant of Carbon, Housing and Goods and Services footprints (but not Food footprint and total ecological footprint). This specific finding affirms the presence of a cultural influence on the China- and Australia-born groups' consumption behaviours in Australia. Individuals who indicated a stronger connectedness with Chinese culture than with the host culture (high scores of CALD Index) were likely to be higher consumers of energy, travel, housing and appliances. The strong connectedness with Chinese culture is a key factor in the display of reputation attained through their success, and in the ostentatious display of possessions such as large dwellings. In other words, these individuals display the Confucian concept of 'mein-tzu' [19] and 'keeping up with the Joneses'.

\subsection{Conclusions}

This paper has shown that culture has an impact on the consumption behaviours of the two groups studied China- and Australia-born residents of Melbourne, Australia. The challenge for subsequent research is to further unravel migrants' ethnic cultures in the context of the host culture. Culture, as documented, influences individuals' actions by 'shaping the tool kit of habits, skills, and styles from which people construct strategies of action' [20]. As culture 'is intimately integrated with action', to unravel what is uniquely cultural will be difficult, as 'cultural retooling (is needed) to adopt new patterns of action' [20]. The challenge of altering culturally-linked consumption behaviours requires a great deal of effort [21]. There is thus a need to identify specific pathways that focus on culturally-induced behavioural change among ethnically identified individuals. There exists a wider challenge for Australian society to develop modes of living that reflect a heightened environmental awareness and a lower ecological impact among its multicultural groups.

\section{Acknowledgements}

This research has been made possible due to the financial support from the Swinburne University of Technology, which granted me a postgraduate scholarship, and the Commonwealth Scientific and Industrial Research Organisation (CSIRO) for a CSIRO Flagship Collaboration Fund Postgraduate Top Up Scholarship (Water for a Healthy Country Flagship). I would like to thank Dr Robyn Sampson for her comments.

\section{References}

[1] Australian Bureau Statistics, ABS 2006, Year Book Australia 2006.

[2] Hong, Y-y, Morris, MW, Chiu, C-y \& Benet-MartÃnez, Vn 2000, 'Multicultural minds: A dynamic constructivist approach to culture and cognition', American Psychologist, vol. 55, no. 7, pp. 709-720.

[3] Phinney, JS 1998, 'Ethnic identity in adolescents and adults', in P Balls Organista, K Chun and G Marin (eds), Readings in ethnic psychology, Routledge, New York, pp. 73-99.

[4] WWF 2014, Living Planet Report 2014, World Wild Fund for Nature, Gland, Switzerland.

[5] Zacarias-Farah, A \& Geyer-Allély, E 2003, 'Household consumption patterns in OECD countries: Trends and figures ', Journal of Cleaner Production, vol. 11, no. 8, pp. 819-827. 
http://dx.doi.org/10.1016/S0959-6526(02)00155-5

[6] Newton, PW \& Meyer, D 2012, 'The determinants of urban resource consumption', Environment and Behavior, vol. 44, no. 1, pp. 107-135.

http://dx.doi.org/10.1177/0013916510390494

[7] Ting, CY 2015, forthcoming, Towards Sustainable Living in Australia's Multicultural Society: An exploration of cultural differences in attitudes to environment and consumption behaviours, PhD thesis, Swinburne Institute for Social Research, Swinburne University of Technology, Melbourne, Australia.

[8] OECD 2011, Greening household behaviour: The role of public policy, OECD.

[9] Lenzen, M, Wierb, M, Cohenc, C, Hayamid, H, Pachaurie, S \& Schaefferf, R 2006, 'A comparative multivariate analysis of household energy requirements in Australia, Brazil, Denmark, India and Japan ', Energy, vol. 31, pp. 181207.

http://dx.doi.org/10.1016/j.energy.2005.01.009

[10] Fielding, KS, Thompson, A, Louis, WR \& Warren, C 2010, Environmental sustainability: Understanding the attitudes and behaviour of Australian households, Queensland Research Centre, Australian Housing and Urban Research Institute, (AHURI).

[11] Stern, PC 1992, 'What psychology knows about energy conservation', American Psychologist, vol. 47, no. 10, pp. 1224-1232.

http://dx.doi.org/10.1037/0003-066X.47.10.1224

[12] Cullen, JB \& Parboteeah, PK 2008, Multinational management: A strategic approach, 4th edn., Thomson/SouthWestern, Mason, Ohio, USA.

[13] Gupta, SR 2009, 'Beyond borders: Leading in today's multicultural world', in MA Moodian (ed.) Contemporary leadership and intercultural competence: Exploring the cross-cultural dynamics within organisations, SAGE Publications Inc., California, pp. 145-158. http://dx.doi.org/10.4135/9781452274942.n12

[14] Chetty, M, Tran, D \& Grinter, RE 2008, 'Getting to green: Understanding resource consumption in the home', UbiComp'08, no. September 21-24, pp. 242-251.

[15] Mont, O \& Plepys, A 2008, 'Sustainable consumption progress: Should we be proud or alarmed?', Journal of Cleaner Production,no. 16, pp. 531-537. http://dx.doi.org/10.1016/j.jclepro.2007.01.009

[16] Centre for Sustainable Economy 2011, Ecological footprint quiz, Centre for Sustainable Economy, viewed 1 May 2011, <http://myfootprint.org/en/cse/>.

[17] Hair, JFJ, Anderson, RE, Tatham, RL \& Black, WC 1995, Multivariate data analysis with readings, 4th edn., Prentice Hall, New Jersey.

[18] Francis, G 2007, Introduction to SPSS for Windows: v15.0 \& 14.0 with notes for studentware, 5th edn., Pearson Education Australia, NSW.

[19] Hu, HC 1944, 'The Chinese concepts of "Face"', American Anthropologist, vol. 46, no. 1, pp. 45-64. http://dx.doi.org/10.1525/aa.1944.46.1.02a00040

[20] Swidler, A 1986, 'Culture in action: Symbols and strategies', American Sociological Review, vol. 51, pp. $273-286$. http://dx.doi.org/10.2307/2095521

[21] Cogoy, M 1999, 'The consumer as a social and environmental actor', Ecological Economics, vol. 28, no. 3, pp. 385398.

http://dx.doi.org/10.1016/S0921-8009(98)00114-1 
TABLE III: Influence of the CALD Index and other expected predictors on total ecological footprint and four components of footprint of China- and Australia-born groups

\begin{tabular}{|c|c|c|c|c|c|c|}
\hline & & & & & & \\
\hline & & $\begin{array}{l}\text { Total ecological } \\
\text { footprint }\end{array}$ & $\begin{array}{l}\text { Carbon } \\
\text { footprint }\end{array}$ & $\begin{array}{c}\text { Food } \\
\text { footprint }\end{array}$ & $\begin{array}{l}\text { Housing } \\
\text { footprint }\end{array}$ & $\begin{array}{l}\text { Goods and } \\
\text { Services } \\
\text { footprint }\end{array}$ \\
\hline Context & Determinant & Beta value & $\begin{array}{l}\text { Beta } \\
\text { value }\end{array}$ & Beta value & $\begin{array}{c}\text { Beta } \\
\text { value }\end{array}$ & Beta value \\
\hline- & (Constant) & - & - & - & - & - \\
\hline Cultural context & CALD Index ${ }^{2}$ & -0.033 & 0.195* & 0.092 & $0.167 *$ & $-0.484 * * *$ \\
\hline & Gender $^{3}$ (Male) & $0.196 * *$ & 0.048 & $0.307 * * *$ & 0.048 & 0.014 \\
\hline & $\operatorname{Age}^{3}$ (45 years or older ) & -0.104 & -0.050 & -0.026 & $-0.136 * *$ & -0.086 \\
\hline Individual & $\begin{array}{l}\text { Education }^{2} \text { (University or } \\
\text { postgraduate) }\end{array}$ & -0.036 & -0.112 & -0.040 & -0.028 & 0.103 \\
\hline structural & Employment $^{2}$ (Employed) & -0.090 & -0.048 & -0.032 & $-0.130 *$ & -0.052 \\
\hline attributes & Income $^{2}$ (Low) & $-0.192 * *$ & -0.022 & -0.032 & $-0.170 * *$ & $-0.295 * *$ \\
\hline & Car ownership ${ }^{2}$ & $0.192 * *$ & $0.154 *$ & 0.093 & 0.043 & 0.137 \\
\hline Individual & $\begin{array}{l}\text { Conservation Behaviours Index } \\
(\mathrm{CBI})^{2}\end{array}$ & $-0.189 * *$ & -0.028 & $-0.254 *$ & -0.066 & -0.071 \\
\hline behaviours & $\begin{array}{l}\text { Resource-efficient Technologies } \\
\text { Index (REI) }{ }^{2}\end{array}$ & -0.166 & $-0.201 *$ & -0.070 & $-0.173 * *$ & 0.011 \\
\hline indexes & $\begin{array}{l}\text { Environmental Awareness Index } \\
(\mathrm{AI})^{2}\end{array}$ & $-0.314 * *$ & $-0.217^{*}$ & -0.092 & $-0.236 * *$ & $-0.253 * *$ \\
\hline $\begin{array}{l}\text { Household } \\
\text { context }\end{array}$ & Household size $^{2}$ & -0.083 & $-0.196 * *$ & 0.028 & 0.026 & -0.015 \\
\hline Dwelling & Tenure $^{3}$ (Home owner) & 0.041 & 0.063 & 0.021 & $0.200 * *$ & -0.100 \\
\hline \multirow[t]{7}{*}{ context } & $\begin{array}{l}\text { Dwelling } \operatorname{size}^{3} \text { (150 square meters or } \\
\text { larger) }\end{array}$ & $0.295^{* *}$ & 0.106 & 0.146 & $0.496 * * *$ & 0.142 \\
\hline & Dwelling type $^{3}$ (Detached dwelling) & 0.037 & 0.041 & -0.059 & $0.227 * * *$ & -0.005 \\
\hline & R Square & 0.360 & 0.297 & 0.211 & 0.619 & 0.364 \\
\hline & Adjusted R Square & 0.284 & 0.214 & 0.118 & 0.573 & 0.289 \\
\hline & Sig. F Change & 0.000 & 0.000 & 0.009 & 0.000 & 0.000 \\
\hline & $\mathrm{R}$ & 0.600 & 0.545 & 0.460 & 0.786 & 0.604 \\
\hline & $\mathrm{F}$ & $\begin{array}{c}4.747 \\
(0.000) \\
\end{array}$ & $\begin{array}{c}3.568 \\
(0.000) \\
\end{array}$ & $\begin{array}{c}2.256 \\
(0.009) \\
\end{array}$ & $\begin{array}{l}13.666 \\
(0.000) \\
\end{array}$ & $\begin{array}{r}4.833 \\
(0.000) \\
\end{array}$ \\
\hline
\end{tabular}

Notes: 1. Standardised Beta coefficients are highlighted in bold face for coefficients which are statistically significant at $* * * p<0.01, * * p<0.05, * p<0.100$ level (which is a lower threshold for small sample)

2. Interval (continuous) level variable

3. Dichotomous variables - more details refer to [7] 